\title{
Circulating CLA+ T lymphocytes as peripheral cell biomarkers in T-cell-mediated skin diseases
}

\author{
Marta Ferran ${ }^{1}$, Ester R. Romeu ${ }^{2}$, Catalina Rincón ${ }^{2}$, Marc Sagristà ${ }^{1}$, Ana M. Giménez Arnau ${ }^{1}$, \\ Antonio Celada ${ }^{2}$, Ramon M. Pujol ${ }^{1}$, Péter Holló ${ }^{3}$, Hajnalka Jókai ${ }^{3}$ and Luis F. Santamaria-Babí ${ }^{1,2}$ \\ ${ }^{1}$ Department of Dermatology, Hospital del Mar, Research Group in Inflammatory Dermatologic Diseases, IMIM, Universitat Autònoma de \\ Barcelona, Barcelona, Spain; ${ }^{2}$ Department of Physiology and Immunology, Universitat de Barcelona, Barcelona, Spain; ${ }^{3}$ Department of \\ Dermatovenerology and Dermatooncology, Semmelweis University, Budapest, Hungary \\ Correspondence: Luis F. Santamaria-Babi, Departament of Fisiologia I Immunologia, Universitat de Barcelona, Facultat de Biologia, UB Avda \\ Diagonal 643, Barcelona 08028, Spain, Tel.: 0034-677375160, e-mail: Luis.santamaria@ub.edu
}

Abstract: $\mathrm{T}$ lymphocytes expressing the CLA antigen constitute a subset of effector memory lymphocytes that are functionally involved in T-cell-mediated cutaneous diseases. Skin-seeking lymphocytes recirculate between inflamed skin and blood during cutaneous inflammation. Many studies in different T-cellmediated inflammatory cutaneous diseases have clearly related their pathologic mechanisms to CLA $+\mathrm{T}$ cells. Based on common features of these cells in different cutaneous disorders mediated by
$\mathrm{T}$ cells, we propose that circulating CLA+T cells could constitute very useful peripheral cellular biomarkers for T-cell-mediated skin diseases.

Key words: associated antigen - biomarker - cutaneous lymphocyte skin-homing - T lymphocyte

Accepted for publication 16 April 2013

\section{Introduction}

Most of the cytokine producing T cells during cutaneous inflammation belong to the memory phenotype (1). Memory T lymphocytes present in the circulation are not distributed randomly to peripheral tissues (2). Specific mechanisms guide those cells to cutaneous locations under homoeostatic conditions in inflammation, infections and cancer. The cutaneous lymphocyte-associated antigen (CLA) is a cell-surface carbohydrate induced by the fucosyltransferase VII-dependent post-translational modification of platelet (P)-selectin glycoprotein ligand 1 (PSGL-1) and interacts with endothelial (E)-selectin. CLA distinguishes human effector memory CD45R0+ T cells $(3,4)$ with cutaneous tropism involved in pathologic mechanisms of T-cell-mediated skin diseases (5). CLA $+\mathrm{T}$ cells are present in approximately $15 \%$ to $20 \%$ of CD3+ cells (6), and most infiltrating $\mathrm{T}$ cells in cutaneous lesions are CLA+, whereas $\mathrm{T}$ cells infiltrating non-cutaneous tissues are CLA- (3). Healthy skin also harbours CLA+ T cells (7).

The CLA antigen is part of a complex multistep molecular interaction between circulating lymphocytes and cutaneous vascular endothelium that takes place during lymphocyte migration to the skin. Proinflammatory mediators expressed under inflammatory conditions, like IL- 1 or TNF- $\alpha$, upregulate the expression of adhesion molecules and chemokines on the surface of endothelial cells (5).

Some studies have shown numerical and phenotypical changes in circulating CLA+ $\mathrm{T}$ cells that are related to cutaneous disease severity and clinical evolution in T-cell-mediated skin diseases $(5,8)$. However, in such cases, CLA $+\mathrm{T}$-cell recirculation between affected skin and blood during cutaneous inflammation has not been fully demonstrated in humans. As mentioned, beside other adhesion molecules and chemokines, CLA $+\mathrm{T}$ cells require the LFA-1/ICAM-1 interaction during their transendothelial migration in vitro $(9,10)$. Information regarding the mode of action of anti-LFA-1 treatments has been obtained from clinical trials in psoriasis and atopic dermatitis (11-13), providing translational evidence in favour of effector memory CLA + T-cell recirculating capacity between skin and blood during cutaneous inflammation. If continuous recirculation occurs between inflamed skin and blood during cutaneous inflammation in psoriasis and atopic dermatitis, blockade of extravasation of $\mathrm{T}$ cells from blood into skin with anti-LFA-1 treatment should affect normal circulating levels of CLA $+\mathrm{T}$ cells. In fact, in both diseases, a rise in circulating CLA $+\mathrm{T}$ cells is observed in parallel to the clinical improvement of inflammation due to treatment $(12,13)$.

Such clinical phenomena might be explained by two mechanisms. First, the LFA-1/ICAM-1 interaction is involved in the transendothelial migration of CLA $+\mathrm{T}$ cells; second, infiltrating CLA+ $\mathrm{T}$ cells recirculate from the lesion to the blood through the thoracic duct and accumulate in the blood (Fig. 1a). Skinactivated CLA $+\mathrm{T}$ cells that recirculate to blood could not extravasate due to the blockade of their adhesion mechanisms and they would accumulate, inducing CLA+ T-cell lymphocytosis (Fig. 1b). Such lymphocytosis present during treatment with anti-LFA-1 can have clinical relevance: a skin relapse may develop after stopping the treatment (11). A similar phenomenon has been observed for a different memory T-cell subset when blocking the alpha4 integrin in multiple sclerosis, leading to lymphocytosis (14).

T-cell skin-homing mechanisms have been extensively studied in the mouse and recently reviewed (15). However, the study of those cells in patients with chronic cutaneous inflammatory diseases is a more complex situation. Understanding immunological mechanisms responsible for skin flares in patients with longstanding atopic dermatitis, or psoriasis, is different from those induced de novo by delayed-type hypersensitivity in a sensitized 
(a)

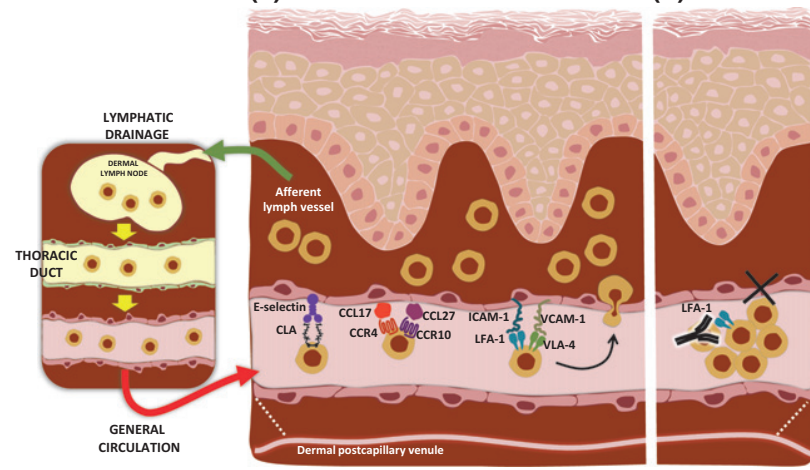

Figure 1. Circulating CLA+ T cells as cellular biomarkers. CLA+ T cells recirculate between blood and skin (a) through specific adhesion and chemotactic mechanisms. Anti-LFA-1 blocking antibodies inhibit the migration of CLA+T cells from blood into skin and cause accumulation of lesion-derived CLA+ T cells in blood (b). Studying peripheral CLA+ T cells allows obtaining information about immune-inflammatory processes taking place in the skin.

mouse to haptens or antigens. The chronicity and maintenance of those T-cell-mediated diseases can reside on antigen-specific memory $\mathrm{T}$ cells present in blood and involved in the skin flares during cutaneous effector phases. For example, in patients with atopic dermatitis or contact dermatitis, circulating effector memory CLA $+\mathrm{T}$ cells, but not CLA-, respond to house dust mites or nickel, suggesting a compartmentalization of the immune response present in periphery (16).

Analysis of the peripheral blood CLA+ T-cell populations provides opportunity to better understand human $\mathrm{T}$-cell-mediated skin diseases. Circulating CLA $+\mathrm{T}$ cells have recirculating capacity, show specificity towards cutaneous antigens/allergens/autoantigens, and their phenotype is influenced by the cutaneous environment to which they have been exposed. Our point of view is that there are evidences from different cutaneous diseases that support the relevance of circulating CLA $+\mathrm{T}$ cells as cellular peripheral biomarkers and as a source of translational knowledge in T-cell-mediated skin diseases.

\section{Psoriasis}

CLA+ $\mathrm{T}$ cells are considered key cellular elements in the mechanism involved in psoriasis lesion formation (17-20). They are present at the initial stage of plaque psoriasis before epidermal hyperplasia takes place $(21,22)$. The percentage of CLA $+\mathrm{T}$ cells in peripheral blood correlates inversely with Psoriasis Area and Severity Index (PASI) and body surface area (BSA) in acute but not in chronic psoriasis (23), suggesting a sequestration of those cells from blood into inflamed skin. In addition, the number of circulating CD4 + CLA + and CD3 + CLA + cells expressing the activation marker HLA-DR is increased in peripheral blood of psoriatic patients with active disease compared to patients with chronic lesions (24). Recently, a novel subset of human skin-homing CLA + CCR6 $+\mathrm{V} \gamma 9 \mathrm{~V} \delta 2 \mathrm{~T}$ cells has been identified (25). As in previous studies, the number of circulating CLA $+\mathrm{V} \gamma 9 \mathrm{~V} \delta 2 \mathrm{~T}$ cells correlated inversely with PASI score and increased with successful treatment.

In psoriasis, CLA $+\mathrm{T}$ cells not only migrate to skin but participate in the initiation of lesion. It has been suggested that CLA $+\mathrm{T}$ cells are present in non-lesional psoriatic skin before epidermal hyperplasia takes place (21). Some infections have been described as relevant triggers of psoriasis, especially Streptococcus pyogenes $(18,26)$ or cytomegalovirus (27). Streptococcal tonsillar infection can induce the onset of the disease or trigger relapses (26). CLA+ $\mathrm{T}$ cells are generated, upon activation by Streptococcus pyogenes superantigens, in tonsils and migrate to psoriatic cutaneous lesions. In fact, an identical and highly restricted TCR usage has been found in CLA+ T cells present in tonsils and psoriatic lesion express of the same patient, suggesting migration of those cells from tonsil to skin lesion (28). Circulating CLA + CD8 + T cells react with keratin peptides that share sequence with streptococcal M proteins (29) and their percentage in peripheral blood correlates with disease severity (30). Interestingly, in psoriatic patients with a previous history of exacerbation after sore throat, a close correlation has been recently demonstrated between the degree of clinical improvement after tonsillectomy and the reduction in the frequency of circulating CLA + CD8 + lymphocytes specific to peptides shared by streptococcal $\mathrm{M}$ proteins and skin keratins (31). The relevance of streptococcal throat infection has been known for more than 50 years (32); recently, it has been demonstrated that psoriatic circulating effector memory CLA $+\mathrm{T}$, but not CLAnegative, upon activation with streptococcal extract secrete Th1/Th17 cytokines and induce keratinocyte activation an hyperplasia (33).

All these studies underline the relevance of studying circulating CLA $+\mathrm{T}$ cells in psoriasis because they are related to pathologic mechanisms in this chronic cutaneous inflammation. This is not surprising because psoriatic lesions produce a great variety of chemokines that can attract circulating CLA $+\mathrm{T}$ cells to cutaneous psoriatic lesions such as CCL20, CCL27, CXCL8, CXCL9, CXCL10, CXCL11 (34) and CXCL16 (35). Several studies have demonstrated that the amount of circulating CLA+ $\mathrm{T}$ cells is altered during effective antipsoriatic treatments $(25,31,36)$. It has been shown in a murine psoriasis model that therapeutic doses of PUVA resulted in a sequestration of CLA + CD25+CD4 + $\mathrm{T}$ cells in lymph nodes, suggesting the migration from peripheral nodes to skin (and vice-versa), where they would induce PUVA therapeutic effect (37). In humans, changes of CLA expression in the periphery have been found to correlate with long-term clinical responsiveness to synchronous balneophototherapy using narrow band UVB light (38). Similarly, regarding TNF-alpha inhibitor biological therapy, a significant difference has been recently found between peripheral CLA expression tendencies of responder and relapsing patients in the induction treatment period (39). These results highlight a potential predictive importance of the CLA molecule in different psoriasis therapies.

\section{Other cutaneous inflammatory diseases}

Several studies have reported that, in different T-cell-mediated cutaneous diseases, the clinical status can induce changes in phenotype, cell numbers or related mechanisms of CLA+ T cells. In atopic dermatitis, circulating CLA $+\mathrm{T}$ cells recognize allergens or bacterial molecules involved in the pathogenesis of eczema development. Their role in atopic dermatitis and other allergic diseases has been recently reviewed $(8,40)$. Circulating CLA+ $\mathrm{T}$ cells are attracted into cutaneous lesions by different chemokines, whose specific receptors are present on the CLA + T-cell surface. Serum levels of CCL17, CCL22 and CCL27 have been correlated with the clinical severity of atopic dermatitis. Circulating CLA $+\mathrm{T}$ cells 
from patients with active atopic dermatitis express T-cell activation markers and spontaneously produce IL-4 (16) and IL-13 (41), as expected for a lymphocyte population that recirculates between inflamed skin and blood.

Neuropeptides are thought to influence the mechanism of cutaneous flares in atopic dermatitis, and stress is a well-known trigger of disease flares. A recent study has demonstrated how calcitonin gene-related peptide, but not other neuropeptides, selectively activates circulating CLA $+\mathrm{T}$ cells from atopic dermatitis patients, inducing IL-13 production in a manner independent of T-cell receptors (42). Considering that CLA $+\mathrm{T}$ cells preferentially produce IL-31, an important cytokine involved in pruritus generation (43), circulating skin-homing $\mathrm{T}$ cells can also be of value as cellular biomarkers of molecular processes involved in T-cell-mediated pruritus.

In non-immediate cutaneous reactions to drugs such as beta-lactams and anticonvulsants, CLA $+\mathrm{T}$ cells are the subset of memory $\mathrm{T}$ cells that respond to those antigens (44). Under re-exposure, those cells express activation markers in parallel to the cutaneous symptoms (45). The CLA antigen is also expressed on the surface of regulatory $\mathrm{T}$ cells (T-regs) implicated in the prevention of acute graft-versus-host disease (aGVHD) after allogeneic stem cell transplantation (ASCT). Increased amount of CLA+ T-regs at engraftment is associated with the prevention of skin aGVHD (46). A threshold value for CLA+ T-regs could be of use to predict important hematopoietic cell transplant (HCT) outcomes and may help to direct the rational use of tissue-specific preventive therapies to decrease clinical aGVHD and improve HCT survival (47). In scleroderma, a new venue of research has been initiated by studying circulating CD $8+$ CLA $+\mathrm{T}$ cells in early stages of the disease. Those cells produce IL-13, accumulate in the lesions and produce cytotoxic granules that may be involved in the early vascular damage present in scleroderma (48).

\section{Skin tumors}

CLA $+\mathrm{T}$ lymphocytes homing to cutaneous lesions play a central role in anti-tumoral immune responses (49). Although the heterogeneous subset of tumor-infiltrating lymphocytes (TILs) in malignant melanoma involves cells with both tumor-stimulating and tumor-inhibiting properties (50), a common feature of these cells is CLA expression (51) accompanied by special combinations of chemokine receptors $(52,53)$. In metastatic lesions, endothelial cell adhesion molecule expression (e.g. E-selectin, the pair of the CLA antigen) markedly declines, which explains decreased skin- and tumor-infiltrating capacity of circulating CLA+ reactive lymphocytes as well as unimpeded tumor progression (54). Similarly, a downregulation of endothelial adhesion molecules and the consequent inhibition of CLA+ lymphocyte extravasation have been reported in epithelial skin cancers (squamous cell carcinoma and basal cell carcinoma) $(55,56)$.

In primary cutaneous T-cell lymphomas, co-expression of CLA and skin-specific chemokine receptors on $\mathrm{T}$ lymphocytes is a requisite for T-cell skin infiltration (49). The distinct clinical behaviour of mycosis fungoides (MF) and Sézary syndrome (SS) might be explained by a different origin of the tumor cells. In MF, the main skin addressins, CLA and chemokine receptor CCR4 guide malignant effector memory $\mathrm{T}$ lymphocytes to the skin. These cells typically lack lymph node homing receptors (CCR7, L-selectin) explaining why tumor cells are primarily found in the skin without circulating in the periphery and infiltrating lymph nodes (57). However, in parallel with progression, tumor cells downregulate skin-specific homing molecules, accumulate in blood and express great amounts of lymph node-homing markers (58). A variable degree of circulating tumor cell CLA expression has been demonstrated in SS with general co-expression of lymph node addressins, referring to the central memory phenotype of malignant lymphocytes. A subset of these cells showing prominent expression of CLA and CCR4 migrates to cutaneous areas (57). A strong correlation has been observed between percentage of CLA+ circulating lymphoma cells and extent of skin symptoms $(59,60)$. These major differences in tumor cell-homing abilities may explain why MF is confined to skin and has an overall better prognosis than SS, with involvement of skin, peripheral circulation, lymph nodes and a general poor clinical outcome (57).

All in all, tumor progression is facilitated by decreased expression of endothelial adhesion molecules in malignant tumors. Enhancing migratory capacity of CLA + reactive immune cells could be beneficial in the therapy. Skin infiltration of CLA+ tumor cells is a key feature of primary cutaneous T-cell lymphomas. Targeted inhibition of tissue-specific tumor cell homing might be of notable therapeutic importance in the future.

In summary, results obtained from different T-cell-mediated skin diseases highlight the relevance of circulating CLA $+\mathrm{T}$ cells. These cells may be a source of information as peripheral cell biomarkers, both in a predictive or retrospective way, as their number and phenotype parallel local cutaneous events and correlate with clinical activity and treatments. In addition, the study of different subsets of CLA $+\mathrm{T}$ cells can bring added value in the biomarker area such as those recently activated lymphocytes (24) or expressing certain chemokine receptors on their surface. Future clinical trials are required to validate the relevance of circulating CLA $+\mathrm{T}$ cells as clinical biomarkers for T-cell-mediated cutaneous diseases.

\section{Acknowledgements}

This work was supported by a grant from the Instituto de Salud Carlos III FEDER (PS09/0222 and PS09/01811). We acknowledge the support of the COST BM0903 Network/SKINBAD (Skin Barrier in Atopic Diseases).

\section{Author contributions}

MF, ER, CR, MS, PH, HJ performed the research; LS, PH, HJ designed research studies; AG, RP contributed essential reagents and tools; LS, PH, HJ analysed the data; LS and PH wrote the paper.

\section{Conflict of interests}

The authors have declared no conflicting interests.

\section{References}

1 Robert C, Kupper T S. N Engl J Med 1999: 341 1817-1828.

2 Sigmundsdottir $H$, Butcher E C. Nat Immunol 2008: 9: 981-987.

3 Picker L J, Michie S A, Rott L S et al. Am J Pathol 1990: 136: 1053-1068.
4 Sallusto F, Lenig D, Forster $R$ et al. Nature 1999: 401: 708-712.

5 Santamaria-Babi L F. Eur J Dermatol 2004: 14: 13-18.

6 Picker L J, Martin R J, Trumble A et al. Eur J Immunol 1994: 24: 1269-1277.
7 Clark R A, Chong B, Mirchandani $\mathrm{N}$ et al. J Immunol 2006: 176: 4431-4439.

8 Santamaria-Babi L F. Chem Immunol Allergy 2006: 91: 87-97.

9 Santamaria Babi L F, Moser R, Perez Soler M T et al. 1995: J Immunol 154: 1543-1550. 
Ferran et al.

10 Mora J R, Von Andrian U H. Curr Top Microbiol Immunol 2006: 308: 83-116.

11 Johnson-Huang L M, Pensabene C A, Shah K R et al. PLoS ONE 2012: 7: e30308.

12 Harper E G, Simpson E L, Takiguchi R H et al. J Invest Dermatol 2008: 128: 1173-1181.

13 Vugmeyster $Y$, Kikuchi T, Lowes M A et al. Clin Immunol 2004: 113: 38-46.

14 Khademi M, Bornsen L, Rafatnia F et al. Eur J Neurol 2009: 16: 528-536.

15 Egawa G, Kabashima K. J Invest Dermatol 2011: 131: 2178-2185.

16 Santamaria Babi L F, Picker L J, Perez Soler M T et al. J Exp Med 1995: 181: 1935-1940.

17 Guttman-Yassky E, Nograles K E, Krueger J G. J Allergy Clin Immunol 2011: 127: 1420-1432.

18 Nestle F O, Kaplan D H, Barker J. N Engl J Med 2009: 361: 496-509.

19 Bowcock A M, Krueger J G. Nat Rev Immunol 2005: 5: 699-711.

20 Schon M P, Boehncke W H. N Engl J Med 2005: 352: 1899-1912.

21 Davison S C, Ballsdon A, Allen M H et al. Exp Dermatol 2001: 10: 280-285.

22 Vissers $\mathrm{W} \mathrm{H}$, Arndtz C H, Muys L et al. Br J Dermatol 2004: 150: 852-859.

23 Ferran M, Gimenez-Arnau A M, Bellosillo B et al. Eur J Dermatol 2008: 18: 647-650.

24 Pont-Giralt M, Gimenez-Arnau A M, Pujol R M et al. J Invest Dermatol 2006: 126: 227-228.

25 Laggner U, Di M P, Perera G K et al. J Immunol 2011: 187: 2783-2793.

26 Valdimarsson $\mathrm{H}$, Thorleifsdottir R H, Sigurdardottir S L et al. Trends Immunol 2009: 30: 494-501.
27 Weitz M, Kiessling C, Friedrich $M$ et al. Exp Dermatol 2011: 20: 561-567.

28 Diluvio L, Vollmer S, Besgen P et al. J Immuno 2006: 176: 7104-7111.

29 Johnston A, Gudjonsson J E, Sigmundsdottir $H$ et al. Clin Exp Immunol 2004: 138: 83-93.

30 Sigmundsdottir H, Gudjonsson J E, Jonsdottir et al. Clin Exp Immunol 2001: 126: 365-369.

31 Thorleifsdottir R H, Sigurdardottir S L, Sigurgeirsson B et al. J Immunol 2012: 188: 5160-5165.

32 Norrlind R. Acta Rheumatol Scand 1955: 1 135-144

33 Ferran M, Galvan A B, Rincon C et al. J Invest Dermatol 2013: 133: 999-1007.

34 Mabuchi T, Chang T W, Quinter S et al. J Dermatol Sci 2012: 65: 4-11.

35 Gunther C, Carballido-Perrig N, Kaesler S et al. J Invest Dermatol 2012: 132: 626-634.

36 Soyland E, Heier I, Rodriguez-Gallego $\mathrm{C}$ et al. $\mathrm{Br}$ J Dermatol 2011: 164: 344-355.

37 Singh $T$ P, Schon $M$ P, Wallbrecht $K$ et al. Exp Dermatol 2012: 21: 228-230.

38 Hollo P, Marschalko M, Temesvari E et al. J Dermatol Sci 2005: 39: 131-133.

39 Jokai H, Szakonyi J, Kontar O et al. Exp Dermatol 2013: 22: 221-223.

40 Ferran M, Santamaria-Babi L F. World Allergy Organ J 2010: 3: 44-47

41 Akdis M, Akdis C A, Weigl L et al. J Immuno 1997: 159: 4611-4619.

42 Antunez C, Torres M J, Lopez S et al. Br J Dermatol 2009: 161: 547-553.

43 Bilsborough J, Leung $D$ Y, Maurer $M$ et al. J Allergy Clin Immunol 2006: 117: 418-425.
44 Blanca M, Leyva L, Torres M J et al. Blood Cells Mol Dis 2003: 31: 75-79.

45 Blanca M, Posadas S, Torres M J et al. Allergy 2000: 55: 998-1004.

46 Engelhardt B G, Jagasia M, Savani B N et al. Bone Marrow Transplant 2011: 46: 436-442.

47 Engelhardt B G, Sengsayadeth S M, Jagasia M et al. Exp Hematol 2012: 40: 974-982.

48 Fuschiotti $\mathrm{P}$, Larregina A T, Ho J et al. Arthritis Rheum 2012: 65: 236-246.

49 Jokai H, Marschalko M, Csomor J et al. Pathol Oncol Res 2012: 18: 749-759.

50 Oble D A, Loewe R, Yu P et al. Cancer Immun 2009: 9: 3

51 Adams D H, Yannelli J R, Newman W et al. Br J Cancer 1997: 75: 1421-1431.

52 Harlin $\mathrm{H}$, Meng $\mathrm{Y}$, Peterson A C et al. Cancer Res 2009: 69: 3077-3085.

53 Richmond A, Yang J, Su Y. Pigment Cell Melanoma Res 2009: 22: 175-186.

54 Weishaupt C, Munoz K N, Buzney E et al. Clin Cancer Res 2007: 13: 2549-2556.

55 Clark R A, Huang S J, Murphy G F et al. J Exp Med 2008: 205: 2221-2234.

56 Verhaegh M, Beljaards R, Veraart J et al. Eur J Dermatol 1998: 8: 252-255.

57 Campbell J J, Clark R A, Watanabe R et al. Blood 2010: 116: 767-771.

58 Krieg C, Boyman O. Semin Cancer Biol 2009: 19: 76-83.

59 Borowitz $\mathrm{M}$ J, Weidner A, Olsen E A et al. Leukemia 1993: 7: 859-863.

60 Heald P W, Yan S L, Edelson R L et al. J Invest Dermatol 1993: 101: 222-226. 